\title{
EFEK BUERGER ALLEN EXERCISE TERHADAP PERUBAHAN NILAI ABI (ANKLE BRACHIAL INDEX) PASIEN DIABETES TIPE II
}

\author{
Ainul Yaqin Salam ${ }^{1}$, Nurul Laili ${ }^{2}$ \\ Sekolah Tinggi Ilmu Kesehatan Hafshawaty Pesantren Zainul Hasan Probolinggo \\ email: ainulyaqin63@gmail.com
}

\begin{abstract}
Abstrak
Resiko disfungsi aliran balik vena pada kaki, neuropati, ulkus diabetikum, gangrene, dan amputasi kaki masih menjadi ancaman serius diabetesi.Tidak hanya berdampak fisik, biaya untuk mengelola dan merawat masalah gangguan perfusi perifer kaki sangat banyak yang merugikan individu dan menjadi beban bagi pembiayaan sosial negara. Buerger Allen Exercise (BAE) adalah latihan gerak yang dilakukan tungkai bawah yang bervariasi serta memanfaatkan gaya gravitasi yang dilakukan secara bertahap dan teratur. Variasi gerakan dan gaya gravitasi pada BAE diharapkan mampu untuk memperbaiki dan meningkatkan sirkulasi darah perifer ke ekstermitas sehingga kebutuhan oksigen sampai pada tingkat sel dibuktikan dengan peningkatan nilai Ankel Brachial Index (ABI). Penelitian dirancang untuk mengetahui efek Vascular Rehabilitation Training Program menggunakan BAE terhadap Perubahan Nilai ABI diabetisi tipe 2. Desain Quasy Experiment digunakan untuk mengkaji ada tidaknya sebab-akibat dari dua variabel yang diteliti dengan pendekatan pre-test and post-test control design. Teknik sampling menggunakan puposive sampling. Terdapat 20 responden yang dibagi menjadi dua kelompok. Pengumpulan data menggunakan skala ABI untuk mengukur perubahan nilai sebelum dan setelah dilakukan BAE. Intervensi dilakukan sebanyak 6 sesi dalam 6 hari latihan dengan durasi 15 menit setiap pertemuan. Hasil penelitian menunjukkan terdapat perubahan nilai ABI yang sangat signifikan setelah melakukan BAE. Penelitian ini membuktikan bahwa metode BAE efektif dalam meningkatkan perfusi perifer pada kaki diabetesi dan dapat menjadi alternatif yang mudah dan murah untuk dilakukan dalam memperbaiki gangguan perfusi khususnya pasien diabetes.
\end{abstract}

Kata kunci: Buerger Allen Exercise (BAE), Ankle Brachial Index (ABI), perubahan nilai ABI

\begin{abstract}
The risk of dysfunction venous return in the legs, neuropathy, diabetic ulcer, gangrene, and leg amputation is still a severe threat to diabetes patients.Not only has a physical impact, the expenditure due to managing and treating impaired peripheral, but peripheral perfusion problem is also very much detrimental to the individual and a burden on the country's social financing. Buerger Allen Exercise (BAE) is an exercise with a variety of active movements on the lower extremities and utilizes the gravitational force carried out in stages and regularly. Movement variations and gravitational effects on the BAE are expected to be able to improve and improve peripheral blood circulation to the extremities so that oxygen demand reaches the cellular level as evidenced by an increase in the value of the Ankle Brachial Index (ABI).The essential aim of this study was to determine the effect of Vascular Rehabilitation Training Programs with $B A E$ on the Value Change of ABI type II diabetes patients. The research design uses Quasy Experiments to assess whether there are causes and effects of the two variables studied with the pre-test and post-test control design approach. The sampling technique uses purposive sampling. Twenty respondents participated in this study apart to groups. Data collection uses the ABI scale to measure changes in values before and after the BAE. The intervention was conducted in 6 sessions in 6 days of training with a duration of 15 minutes per meeting. The results showed that there were significant changes in ABI values between before and after conducting the BAE. This study proves that BAE method is effective in improving peripheral perfusion in diabetic feet and can be an easy and straightforward alternative to improve perfusion disorders, especially in patients with diabetes.
\end{abstract}

Keyword: Buerger Allen Exercise (BAE), Ankle Brachial Index (ABI), changes of ABI Value 


\section{PENDAHULUAN}

Pada tahun 2017 International Diabetes Federation (IDF) melaporkan bahwa dari total 166.531.000 penduduk dewasa Indonesia terdapat 10.276.100 orang dengan penyakit diabetes mellitus (DM). Angka di atas mengalami tren yang meningkat dari tahun sebelumnya. IDF juga memprediksikan angka penderita diabetes pada lima sampai 10 tahun mendatang akan semakin meningkat seiring dengan semakin buruknya pengaruh globalisasi (IDF, 2017). Lebih lanjut, data Kementerian Kesehatan Republik Indonesia menyatakan bahwa saat ini Indonesia mengalami krisis kesehatan yang diakibatkan oleh Penyakit Tidak Menular (PTM) khususnya penyakit DM yang memiliki kecenderungan epidemi meningkat yang beresiko mengalami komplikasi seperti stroke, serangan jantung, gagal ginjal bahkan kematian (Kemenkes RI, 2017)

Penyakit DM dengan komplikasinya telah menjadi salah satu penyebab kematian terbesar di Indonesia. DM bertanggung jawab terhadap semakin meningkatnya jumlah kematian yang diakibatkan penyakit tidak menular di Indonesia.. Tidak hanya itu pembiayaan perawatan penyakit diabetes sangat besar hal ini dibuktikan dengan besarnya jumlah klaim jaminan dana sosial (BPJS) dari tahun ke tahun. Dari sekian banyak komplikasi yang dapat dialami oleh penderita diabetes, gangguan perfusi perifer pada kaki merupakan keluhan yang paling sering dialami.

Gangguan perfusi perifer pada kaki yang tidak ditangani dengan benar dapat mengakibatkan terjadinya obstruksi pada vena dan neuropati. Terhambatnya aliran darah (blood flow) pada vena dapat menyebabkan obstruksi arus balik vena dalam melawan gravitasi. Disfungsi aliran balik vena pada akhirnya akan mengakibatkan terjadinya komplikasi luka diabetes (diabetic ulcer) bahkan jika perawatan tidak segera dilakukan akan mengakibatkan amputasi yang menambah kualitas hidup penderitanya semakin menurun (Rosales, Velderrain, Padilla, Choe, dan Hargens, 2013).

Penyakit DM adalah penyakit kronis yang membutuhkan perubahan pola perilaku kesehatan (changes behavior) ke arah yang lebih baik. Changes behavior dapat diinisiasi oleh adanya edukasi, informasi dan atau memberdayakan pasien sehingga memiliki kemampuan merubah perilaku dengan bantuan dari petugas kesehatan. Perubahan pola perilaku memungkinkan penderitanya memiliki kemandirian yang baik dalam usahanya mencapai kesejateraan kesehatan. BAE adalah intervensi yang dapat diajarkan oleh petugas kesehatan khususnya perawat kepada diabetes yang memiliki komplikasi gangguan perfusi perifer pada ekstermitas bawah yang cukup banyak diteliti dan memberikan efek positif pada perbaikan komplikasi perfusi perifer di kaki (Aruna \& Thenmozi, 2015).

$B A E$ adalah latihan gerak pada tungkai bawah yang bervariasi dan gerakan tungkai bawah yang memanfaatkan gaya gravitasi yang dilakukan secara bertahap dan teratur (Chang, et al., 2015). Manfaat dan keuntungan penggunaan atau pemberian $B A E$ telah cukup banyak diteliti, dan memberikan manfaat yang cukup signifikan dalam mengurangi keluhan nyeri (intermitten caludicatio). Selanjutnya, Hassan \& Mehani, 2012) menyatakan bahwa $B A E$ juga memiliki efek positif meningkatkan sirkulasi darah perifer ke ekstermitas sehingga meningkatkan kebutuhan oksigen dan zat nutrisi yang diperlukan untuk metabolisme sampai pada tingkat sel.

$B A E$ diharapkan mampu memberikan perubahan nilai $\mathrm{ABI}$ menjadi lebih baik dari sebelumnya, seperti pada penelitian sebelumnya yang menyimpulkan bahwa $B A E$ dapat meningkatkan sirkulasi (blood flow) di jaringan perifer ekstermitas bawah (Hassan \& Mehani, 2012). Chang, et al., (2015) juga menyatakan bahwa $B A E$ memiliki manfaat yang besar pada perbaikan perfusi pada kaki khususnya kaki diabetes yang dilakukan secara periodik dan teratur. Tujuan penelitian ini adalah menganalisis efek dari $B A E$ terhadap perubahan nilai $\mathrm{ABI}$ diabetesi tipe 2 .

\section{METODE PENELITIAN}

Studi quasy experimental dengan komparasi dua kelompok pembanding dirancang untuk dilakukan pre-test dan post test. Total 20 responden yang dibagi menjadi kelompok intervensi dan kelompok kontrol. Purposive sampling digunakan untuk mengambil sampel. Kriteria inklusi responden yaitu pasien diabetes tipe II dengan pengobatan teratur, skor nilai ABI 0,4-0,89, berumur 40-60 tahun baik laki-laki 
maupun perempuan dan mengikuti seluruh program latihan yang telah disetujui bersama.

Kriteria eksklusi yaitu responden yang tidak mengikuti proses penelitian secara lengkap dan skor nilai ABI kurang dari 0,4 dan atau lebih dari 1,3. Pengumpulan data dibagi menjadi dua yaitu data demografi dan data skor ABI. Skor ABI didapatkan dengan membagi tekanan darah sistolik kaki (dorsalis pedis) dengan tekanan darah sistolik lengan (brachial) dengan menggunakan sphygmomanometer.Interpretasi nilai ABI normal (0,9-1,3), obstruksi ringan (0,71-0,89), obstruksi sedang $(0,41-0,69)$ dan obstruksi berat (kurang dari $0,4)$.

Intervensi diberikan perlakuan sebanyak 6 kali selama 6 hari dengan durasi 15 menit setiap kali pertemuan. Skala ABIdiukur sesuai SPO (Standar Prosedur Operasional) yang sudah ditentukan dengan menggunakan stetoskop dan Doppler. Pembuktian hipotesi menggunakan uji statistikPaired T-Test. Penelitian ini dilakukan di Desa Karangren Kecamatan Krejengan Kabupaten Probolinggo pada tanggal 12 Juni-18 Juni 2019.

\section{HASIL DAN PEMBAHASAN}

\section{Hasil Penelitian}

Hasil penelitian ini akan memaparkan tentang efek dari latihan Buerger Allen Exercise yang dilakukan oleh kelompok intervensi terhadap perubahan nilai ABI (Ankle Brachial Index) pada penderita DM tipe II. Data akan disajikan dalam bentuk tabel dan narasi.

\section{Karakteristik Responden}

Tabel 1. Karakteristik Responden antara Kelompok Intervensi dan Kelompok Kontrol $(\mathrm{n}=20)$

\begin{tabular}{lcccc}
\hline \multirow{2}{*}{ Variabel Demografi } & \multicolumn{2}{c}{ Intervensi } & \multicolumn{2}{c}{ Kontrol } \\
\cline { 2 - 4 } & No. & $\%$ & No. & $\%$ \\
\hline Umur & & & & \\
30-35 tahun & 0 & 0 & 1 & 10 \\
36-40 tahun & 0 & 0 & 3 & 30 \\
41-45 tahun & 4 & 40 & 1 & 10 \\
45-50 tahun & 6 & 60 & 5 & 50 \\
Gender & & & & \\
Laki-laki & 7 & 70 & 4 & 40 \\
$\quad$ Perempuan & 3 & 30 & 6 & 60 \\
Status pernikahan & & & & \\
$\quad$ Nikah & 10 & 100 & 10 & 100 \\
Belum Nikah & 0 & 0 & 0 & 0 \\
Durasi menderita DM & & & & \\
5-10 tahun & 4 & 40 & 8 & 80 \\
11-15 tahun & 6 & 60 & 2 & 20 \\
16-20 tahun & 0 & 0 & 0 & 0 \\
21-25 tahun & 0 & 0 & 0 & 0 \\
Rokok & & & & \\
Merokok & 7 & 70 & 4 & 40 \\
Tidak Merokok & 3 & 30 & 6 & 60 \\
\hline
\end{tabular}

Sebagian besar rata-rata umur penderita DM pada kelompok intervensi berada pada kisaran umur 45-50 tahun dan hal yang sama terjadi pada kelompok kontrol juga pada rentang umur 45-50 tahun. Berdasarkan durasi pasien menderita DM masing-masing 12 tahun dan 7 tahun pada kelompok intervensi dan kontrol. Riwayat kebiasaan merokok pada kedua kelompok sebanyak $11(55 \%)$.

Tabel 2. Efek $B A E$ terhadap Perubahan Nilai ABI $(\mathrm{n}=20)$

\begin{tabular}{ccccccc}
\hline \multirow{2}{*}{ Grup } & \multicolumn{2}{c}{ Mean } & \multicolumn{2}{c}{ SD } & Paired T- & P Value \\
\cline { 2 - 4 } & Pre test & Post Test & Pre Test & Post Test & & \\
\hline Intervensi & 0,7263 & 0,9021 & 0,0543 & 0,0764 & 9,102 & $\begin{array}{c}<0,05 \\
\text { Signifikan } \\
\text { Kontrol }\end{array}$ \\
& 0,8342 & 0,8321 & 0,0498 & 0,0674 & 1,002 & $\begin{array}{c}>0,005 \\
\text { Tidak } \\
\end{array}$ \\
\hline
\end{tabular}

Tabel 2 menunjukkan perbedaan uji statistik mean dan standart deviasi kedua kelompok setelah perlakuan diberikan. Hasil uji menunjukkan adanya perubahan nilai mean kelompok intervensi yang sangat signifikan jika dibandingkan dengan perubahan mean pada kelompok kontrol yang tidak signifikan. Masing-masing standart deviasi adalah 0,0498 dan 0,0543. Selisih mean pada kedua kelompok jelas menunjukkan bahwa kelompok intervensi memiliki selisih mean nilai ABI yang 
tinggi yang berarti ada perubahan nilai ABI yang signifikan. Hasil mean diketahui bahwa perubahan nilai $\mathrm{ABI}$ pada kelompok intervensi lebih baik dari kelompok kontrol dengan signifikansi $\mathrm{p}$ value $(0,000)$ yang berarti terdapat perbedaan pengaruh yang signifikan perubahan nilai $A B I$ pada kelompok intervensi dan kelompok kontrol.

\section{Pembahasan}

\section{a. Karakteristik Responden}

Rata-rata usia responden pada kedua kelompok menunjukkan rentang usia antara 45- 50 tahun. Penelitian Rac-Albu, et al (2014) juga menyimpulkan bahwa penyakit DM sering terjadi pada rentang usia 45-50 tahun. Sejealan dengan hasil penelitian sebelumnya, penelitian Jannoo, et al (2015) melaporkan adanya korelasi yang cukup signifikan antara umur dengan kejadian DM pada kelompok umur 45 tahun dikarenakan proses penuaan yang menyebabkan penurunan fungsi fisiologis termasuk penurunan fungsi pankreas dan terjadinya retensi hormon insulin, sehingga kemampuan regulasi glukosa darah tidak efektif. Hiperglikemia yang tidak terkontrol menyebabkan peningkatan resiko komplikasi kronik, baik makrovaskuler maupun mikrovaskuler salah satunya adalah gangguan perfusi jaringan perifer.

Merujuk pada hasil penelitian diketahui bahwa rata-rata responden memiliki durasi riawayat DM selama 7 tahun. Diabetesi yang memiliki riwayat DM lebih dari 5 tahun memiliki risiko lebih besar terjadinya komplikasi, salah satunya adalahaterosklerosis. Komplikasi aterosklerosis sebagian besar terjadi pada kaki (makrovaskuler). Aterosklerosis yang tidak ditangani dengan baik akan menyebabkan tersumbatnya (obstruksi) pembuluh darah arteri dan atau vena pada kaki yang berakibat timbulnya gangguan aliran darah (blood flow) pada kakinya. Gangguan perfusi perifer pada kaki yang diderita pasien DM yang berkepanjangan menyebabkan kematian saraf (neuropati) pada kaki penderita DM sehingga menyebabkan berkurangnya dan atau hilangnya sensasi peraba pada kakinya. Sebagian besar diabetesi yang berkurang atau bahkan hialng sensasi perabanya di kaki tidak sadar bahwa kakinya telah terluka dan menimbulkan terjadinya ulkus. Penelitian Sinaga, M., \& Hiswani, J (2012) dan penelitian Alvarsson, et al (2012) menunjukkan bahwa terdapat hubungan yang cukup kuat antara lama seseorang menderita DM dengan tingkat resiko terjadinya komplikasi diabetes melitus salah satunya adalah komplikasi berupa gangguan perfusi jaringan perifer kaki bahkan timbulnya ulkus diabetikum.

Hasil penelitian menunjukkan dari 20 responden pada dua kelompok didapatkan yang merokok sebanyak 11 (55\%). Penelitian Chang, et al (2015) menyimpulkan bahwa gangguan perfusi perifer akan semakin buruk pada penderita DM yang memiliki riwayat merokok yang lama. Semakin lama penderita DM terpapar oleh rokok, semakin buruk penurunan nilai ABI. Zat racun pada rokok akan menyebabkan rusaknya endotel pembuluh darah yang meningkatkan resiko aterosklerosis semakin tinggi. Nikotin dalam rokok menyebabkan peningkatan hormon adrenalin. Hormon adrenalin dapat mengubah metabolism lemak dalam darah yang menurunkan kadar HDL. Peningkatan hormone Adrenalin juga mengakibatkan menurunnya kerja jantung dan kerusakan endotel darah sehingga arteri koroner jantung menjadi sempit (spasme). Tidak hanya itu, adrenalin berperan penting dalam proses terbentuknya trombosit dalam darah yang berakhir pada penyempitan pembuluh darah baik mikrovaskuler dan makrovaskuler (Alvarsson, et al., 2012). Kesimpulan yang dapat diambil bahwa zat racun (nikotin) dalam rokok berdampak pada kerusakan dinding pembuluh darah (endotel) yang dapat meningkatkan resiko aterosklerosis. Aterosklerosis yang terjadi mempermudah terjadinya gangguan perfusi perifer kaki penderita DM sehingga berakibat pada menurunnya nilai ABI dan mempermudah kaki terjadi ulkus diabetik.

\section{b. Perbedaan Selisih Rata-Rata Nilai ABI}

Hasil penelitian menunjukan adanya perbedaan selisih rata-rata nilai $\mathrm{ABI}$ setelah diberikan $B A E$ pada kedua kelompok dengan nilai $\mathrm{p}$ value 0.00 . Penelitian Lamkang ((2017) menyatakan bahwa efek dari $B A E$ secara efektif meningkatkan sirkulasi darah perifer. Efek yang dirasakan oleh penderita DM setelah melakukan burger allen exercise adalah meningkatnya kemampuan dalam berjalan, mengurangi rasa nyeri (intermitten claudicatio), mengurangi rasa kesemutan, mengurangi edema tungkai yang dapat 
dinilai dari meningkatnya keadekuatan sirkulasi perifer dari perubahan nilai Ankle Brachial Index (ABI). Keadekuatan sirkulasi perifer oleh $B A E$ merupakan hasil dari metode dan variasi latihan dengan mengoptimalkan gerakan pada tungkai bawah sehingga terjadi proses muscle pumpdan gerakan yang memanfaatkan gaya gravitasi sehingga terjadi kelancaran gerakan aliran darah pada tungkai bawah menuju jantung dan seluruh tubuh.

Variasi gerakan pada $B A E$ menggabungkan teknik gerakan yang mengarah pada terjadinya muscle pump oleh pergerakan otot kaki dan memanfaatkan gaya gravitasi pada kaki. Gerakan kaki yang memanfaatkan gravitasi mempermudah aliran balik vena pada kaki dan membantu pembuluh darah melakukan pengosongan dan mengisi kolom darah secara bergantian, sehingga transportasi darah di area kaki menjadi lancar baik menuju maupun arah balik vena ke organ jantung (Khan, et al 2008). Posisi berdiri menyebabkan aliran darah menjadi lancar menuju kearah splanchnic, panggul dan pembuluh darah kaki. Pergerakan tersebut diakibatkan oleh adanya gravitasi terhadap perubahan postural yang menghasilkan pergerakan darah. Sejalan dengan penelitian sebelumnya, Vijayabarathy (2014) menyatakan bahwa $B A E$ berperan penting terhadap proses penyembuhan luka kaki diabetik. $B A E$ dapat meningkatkan sirkulasi pembuluh darah perifer dengan tehnik perubahan gravitasi pada ekstremitas bawah disertai kontraksi otot melalui variasi gerakan dorso fleksi dan plantar fleksidari pergelangan kaki.

$B A E$ menjadi salah satu modalitas latihan yang dapat diterapkan dan diajarkan kepada seseorang dengan gangguan perfusi jaringan perifer kaki khususnya diabetesi karena prosedur latihan BAE mudah, murah dan efisien dilakukan. Kemandirian (self care) diabetesi dalam merawat dan mencegah komplikasi makrovaskuler menjadi penting dan menjadi perhatian perawat mengingat komplikasi yang akan ditanggung oleh diabetesi menjadi beban bagi dirinya dan keluarga. Perawat harus berpandangan bahwa pasien DM yang memiliki gangguan perfusi perifer pada kakinya berpotensi mampu merawat diri (self care) dalam memenuhi kebutuhan hidup, memelihara kesehatan, dan mencapai kesejahteraan. Kesehatan dan kesejahteraan yang optimaldapat dicapai jika seseorang memiliki kemampuan dan kemandirian memenuhi kebutuhannya (Orem dalam Tomey \& Alligood, 2014).

\section{c. Efek $B A E$ terhadap Perubahan Nilai ABI}

Terdapat perbedaan yang signifikan nilai ABI pada kelompok intervensi sebelum dan setelah dilakukan $B A E$. Sebaliknya tidak ada perbedaan signifikan nilai ABI pada kelompok kontrol. Sejalan dengan penelitian Aruna dan Thenmozi (2015) yang melaporkan bahwa terdapat peningkatan kadar Nitric Oxid yang berperan penting dalam peningkatan perfusi perifer di kaki setelah dilakukan $B A E$ selama 3 bulan. Hal ini juga didukung oleh penelitian Chang, et al (2015) yang menyimpulkan bahwa hambatan aliran darah pada kaki diabetesi karena proses penyakit DM dapat diatasi dengan BAE.

Beberapa hasil penelitian yang menggunakan $B A E$ sebagai latihan untuk pasien DM terbukti dapat meningkatkan aliran darah (blood flow) melalui gerakan-gerakan yang memanfaatkan kontraksi otot dan gaya gravitasi. Gerakan tungkai bawah yang dilakukan dapat meningkatkan sirkulasi pembuluh darah perifer. Muscle pump dihasilkan oleh gerakan kaki yang menyebabkan kontraksi otot kaki sehingga terjadi mekanisme pompa pembuluh darah oleh kontrkasi otot. Gerakan-gerakan pada $B A E$ berfungsi untuk "memompa" pembuluh darah dengan pergerakan otot tungkai terhadap tekanan aliran darah sehingga aliran darah ke jantung dan ke seluruh tubuh menjadi lancar (Hassan \& Mehani, 2012).

$B A E$ yang dilakukan secara konsisten dapat meringankan dan memperbaiki gangguan perfusi perifer pada kaki pasien DM. $B A E$ memperbaiki dinding pembuluh darah (endotel) dengan cara meingkatkan Nitric Oxid (NO) dan pada akhirnya memperbaiki aterosklerosis dan meningkatkan kemampuan pembuluh darah dalam beradaptasi terhadap resiko aterosklerosis berulang (Vijayabarathy dan Hermavathi, 2014).

$B A E$ efektif meningkatkan nilai ABI. Variasi gerakan yang menyebabkan terjadinya muscle pump dan memanfaatkan gaya gravitasi pada tungkai secara efektif dapat meningkatkan perfusi pada kaki. Gerakan dorsofleksi dan plantar fleksi 
pada kaki yang dilakukan sesuai dengan protokol dan prosedur mampu mengatasi bendungan aliran darah akibat obstruksi aterosklerosis. $B A E$ dapat merelaksasi otot-otot pada tungkai dan juga membuat otot berkontraksi dan menstimulasi pengeluaran Nitric Oxid (NO) pembuluh darah, meningkatkan fleksibiltas pembuluh darah dan akhirnya sirkulasi darah optimal membawa oksigen dan nutrisi untuk kebutuhan metabolisme. Vaskularisasi lancar yang diakibatkan oleh $B A E$ akan membuat tekanan aliran darah pada tungkai (dorsalis pedis) meningkat sehingga rasio perbandingan dengan tekanan pada lengan (brachial) pun juga akan meningkat. Meningkatnya rasio perbandingan tekanan darah tersebut akan meningkatkan rasio perbandingan tekanan dorsalis pedis dan brachialis, dengan kata lain meningkatnya nilai ABI yang berarti resiko penderita DM mengalami neuropati dan ulkus semakin berku;rang (Zhang, et al., 2009).

\section{KESIMPULAN DAN SARAN}

\section{Kesimpulan}

Temuan penelitian ini mengungkapkan bahwa peningkatan yang signifikan perfusi ekstremitas bawah setelah melakukan $B A E$. Metode $B A E$ terbukti memberikan efek terhadap perubahan nilai $A B I$ yang berarti meningkatkan perfusi ekstremitas bawahdi antara pasien dengan diabetes mellitus dengan gangguan perfusi sebelumnya.

\section{Saran}

Penelitian selanjutnya yang dapat dilakukan adalah memodifikasi metode dan ukuran sampel yang lebih besar serta intervensi yang lebih lama. Hasil penelitian diharapkan mampu memberikan gambaran kepada tenaga kesehatan profesional yang terlibat dalam praktik pendidikan kesehatan pada pasien diabetes khususnya bagi tenaga kesehatan yang memiliki perhatian pada masalah gangguan perfusi kaki pada pasien DM.

\section{REFERENSI}

Alligood, M.R. \& Tomey, A.M. (2010). Nursing theorists and their work. Seven.United States of America: Elsevier.
Alvarsson, A., Sandgren, B., Wendel, C., Alvarsson, M. and Brismar, K. (2012). A Retrospective Analysis of Amputation Rates in Diabetic Patients: Can Lower Extremity Amputations Be Further Prevented? Cardiovascular Diabetology, 18 (11). 1-11.

Aruna, S \& Thenmozi, P. (2015). Effectiveness of Allen Buerger Exercise in Preventing Peripheral Arterial Disease Among People with Type II Diabetes Mellitus. International Journal of Pharma and Bio Science, 6 (2), 966-970.

Chang, CF., Chang, CC., Hwang, S.L., \& Chen, M.Y. (2015). Effect of Buerger Exercise Combine Health Promoting Program on Peripheral Neurovasculopathty Among Community Resident at High-Risk fo Diabetic Foot Ulcer. Worldviews on Evidence-Based Nursing, 12 (3), 145-53.

Conti, A.A., Macchi, C., Conti, A. and Gensini, G.F. (2007). Relationship between Physical Activity and Cardiovascular Disease:Selected Historical Highlights. The Journal of Sports Medicine and Physical Fitness, 47 (1), 84-90.

Dinas Kesehatan Kabupaten Probolinggo (2014). Selayang Pandang Bidang Kesehatan Kabupaten Probolinggo Tahun 2014. Probolinggo: Dinas Kesehatan Kabupaten Probolinggo.

Hassan, S \& Mehani, M. (2012). Comparison Between Two Vascular Rehabilitation Training Program for Patient with Intermittent Claudication as a Result of Diabetic Atherosclerosis. International Journal Faculty of Physical Therapy, Cairo. 17 (1), 7-16.

International Diabetes Federation (IDF). International Diabetes Federation: Diabetes ATLAS Seventh Edition. (2015). Epub ahead of print 2015. DOI: 10.1289/image.ehp.v119.i03.

Jannoo Z, Yap BW, Musa KI, et al. (2015). An Audit of Diabetes-Dependent Quality of Life in Patients with Type 2 Diabetes Mellitus in Malaysia. Quality of Life Research, 24 (9), 2297-2302.

Kementerian Kesehatan Republik Indonesia. Hasil Utama Riskesda. (2013). Indonesia 2015. Jakarta: Kementerian Kesehatan RI. Badan Penelitian dan pengembangan Kesehatan, 2013. 
Kementerian Kesehatan RI. (2016). Profil Kesehatan Indonesia 2015. Jakarta: Kementerian Kesehatan RI, 2016. Epub ahead of print 2016. DOI: 351.077 Ind.

Khan TH, Faruuqui FA, Niazi K. (2008). Critical Review of The Ankle Brachial Index. Current Cardiology Review, 4 (2), 101-106.

Sinaga, M., \& Hiswani, J. (2012). Karakteristik Penderita Diabetes Mellitus Dengan Komplikasi yang Dirawat Inap di Rumah Sakit Vita Insani Pematangsiantar. Fakultas Kesehatan Masyarakat Universitas Sumatera Utara.

World Health Organization. Prevalence of Diabetes in Indonesia. 2016.
World Health Organization. (2016). Global Report on Diabetes. ISBN 2016, 978: 88.

Vijayabarathy M, Hermavathi V. Buerger Allen Exercise for type 2 Diabetes Mellitus Foot Ulcer Patients. International Journal of Innovative Research, Engineering, and Technology, 3 (12), 243-250.

Zhang, R.H., Jiang, W.Y., Liu, J.J., Li, F.Y., Liu, H.E. and Zhu, C.Y. (2009). Effect of Buerger Training on Hemorheology for Patients with Multiple Fractures in Lower Extremities after Internal Fixation, Nursing and Rehabilitation Journal, 8 (11), 903-905. 